\title{
CONSCIÊNCIA FONOLÓGICA E O LÚDICO NA EDUCAÇÃO INFANTIL:CONTRIBUIÇÕES DO PSICOPEDAGOGO INSTITUCIONAL.
}

\author{
PHONOLOGICAL AWARENESS AND LUDIC IN EARLY CHIDHOOD \\ EDUCATION :THE INSTITUCIONAL PSYCHOPEDAGOGIST CONTRIBUTIONS \\ TO THE PROCESS.
}

\author{
CONSCIENCIA FONOLÓGICA Y EL LÚDICO EN LA EDUCACIÓN \\ INFANTIL:CONTRIBUICIONES DEL PSICOPEDAGOGO INSTITUCIONAL.
}

\author{
Karina Ap Ramos da Silva \\ Pós-Graduação em Psicopedagogia \\ Faculdades Integradas de Jaú \\ kazinhafriend@gmail.com \\ Fábio Henrique Pinheiro \\ Fonoaudiólogo - UNESP - Marília \\ Doutor em Educação FFC / UNESP - Marília \\ fabiohenriquepinheiro@yahoo.com.br
}

\begin{abstract}
RESUMO
Inúmeros são os fatores que influenciam na aquisição de conhecimentos, principalmente durante o processo de alfabetização. Contudo essa apropriação de conhecimentos nem sempre ocorre de maneira linear e durante processo de alfabetização as dificuldades podem se fazer presentes. Diante destas peculiaridades da aprendizagem, um trabalho multiprofissional é fundamental para lidar com as possíveis lacunas existentes em âmbito escolar. Dessa forma o trabalho psicopedagógico em cunho institucional se faz pertinente, pois este profissional embasado em métodos e técnicas específicas pode oferecer orientações adequadas aos docentes e contribuir de maneira preventiva para a superação de dificuldades de aprendizagem e para o êxito educacional desses escolares.Uma das bases essenciais para a alfabetização é consciência fonológica pois esta possibilita a percepção e reflexão sobre a estrutura da língua favorecendo e estimulando a aprendizagem em pré escolares, no entanto, este trabalho de estimulação da consciência fonológica na Educação infantil deve preconizar a utilização do lúdico, condizendo com a faixa etária deste público alvo em questão,tornando-se um recurso prazeroso e valioso na aprendizagem durante a Educação Infantil e nos anos posteriores.
\end{abstract}

Palavras-chaves: Psicopedagogia. Consciência Fonológica. Ludicidade.

\section{ABSTRACT}

Many factors may cause influence over the knowledge acquisition process, especially during the literacy process. However, this appropriation of knowledge does not always occur in a linear wayand during the literacy process difficulties might present themselves. In face of those particular singularities of learning, a multiprofessional work is fundamental to deal with the possible gaps in the school environment. Therefore, the psycho-pedagogical work in 
institutional terms is relevant, since this professional grounds his or her practice on specific methods and techniques that may offer adequate guidance to teachers and contribute in a preventive way to overcome learning disabilities and to the educational success of these students. One of the essential groundings regarding literacy is phonological awareness, because it allows the perception and reflection over the structure of language favoring and stimulating learning in preschoolers, however, this work of stimulation of phonological awareness in children's education should advocate the use of playfulness, the age range of this target audience, making it a pleasurable and valuable resource in learning during Early Childhood Education and in later years.

Keywords: psychopedagogy. Phonologicalawareness. Playfulness.

\section{RESUMEN}

Muchos factores pueden influir en el proceso de adquisición de conocimiento, especialmente durante el proceso de alfabetización. Sin embargo, esta apropiación del conocimiento no siempre ocurre de forma lineal y durante el proceso de alfabetización pueden presentarse dificultades. Frente a esas singularidades particulares de aprendizaje, un trabajo multiprofesional es fundamental para enfrentar las posibles brechas en el entorno escolar. Por lo tanto, el trabajo psicopedagógico en lo ámbito institucional es relevante, ya que este profesional fundamenta su práctica en métodos y técnicas específicos que pueden ofrecer una orientación adecuada a los docentes y contribuir de manera preventiva a superar las discapacidades de aprendizaje y al éxito educativo de estos estudiantes. Una de las bases esenciales de la alfabetización es la conciencia fonológica, ya que permite la percepción y reflexión sobre la estructura del lenguaje favoreciendo y estimulando el aprendizaje en preescolares, sin embargo, este trabajo de estimulación de la conciencia fonológica en la educación infantil debe abogar por el uso de la diversidad de la variación de edad de este público, por lo que se configura como un recurso placentero y valioso en el aprendizaje durante la Educación de la Primera Infancia y en años posteriores.

Palabras clave: Psicopedagogía. Conciencia fonológica. Alegría.

\section{INTRODUÇÃO}

A incessante busca pela qualidade do ensino permeia toda a história da educação, tornando-se cada vez mais comum a busca por práticas pedagógicas que supram tal necessidade e que de maneira efetiva potencializem a aprendizagem fazendo desta uma aprendizagem significativa para as crianças.Pesquisas demonstram que as vivências de qualidade durante a Educação Infantil são indicadores de bom desenvolvimento e um aspecto positivo no processo de escolarização básica (OLIVEIRA.Z .2012).

Mediante a isto, este artigo tem como objetivo investigar ainda que de maneira sucinta, a importância do estímulo a consciência fonológica na Educação Infantil de maneira lúdica e seus benefícios para a aprendizagem ,demonstrando por meio de estudo bibliográfico a 
existência de uma relação de reciprocidade entre a consciência fonológica e o aprendizado da leitura e da escrita, assim como ressaltar o papel do Psicopedagogo em âmbito institucional, pois por meio de um olhar diferenciado sobre a aprendizagem significativa, ou seja, uma visão multidimensional da aprendizagem,este profissional pode contribuir para o êxito escolar e desenvolver diferentes aspectos inerentes a aprendizagem.,como referido por Miranda, 2009.

\section{CONTRIBUIÇÃO DO PSICOPEDAGOGO INSTITUCIONAL E A APRENDIZAGEM}

O início da vida escolar de uma criança constitui-se em um momento marcante pois a mesma se depara com um mundo novo onde, por meio de vivencias diferenciadas constrói seu conhecimento e sua percepção de mundo. A educação infantil é uma etapa de suma importância para esse desenvolvimento integral da criança, pois contempla uma série de informações e princípios que nortearão uma base sólida para a construção de novos saberes nos anos escolares subsequentes. Como reitera a LDB 1996:

A Educação Infantil "tem como finalidade o desenvolvimento integral da criança até 6 anos de idade em seus aspectos físico, psicológico, intelectual e social, complementando a ação da família e da comunidade" (art. 29 da LDB).

O desenvolvimento integral em suma deve abarcar uma serie de fatores que contribuirão para a tão almejada qualidade da educação como um todo e em especial a educação infantil que caracteriza-se como uma das etapas de escolarização mais importantes, que deve ser planejada ,considerando aspectos como a faixa etária envolvida , grau de autonomia dos educandos e vivencias anteriores construídas dentro e fora da escola (Oliveira 2012.p.44)

SANTOS enfatiza que:

A Educação Infantil se caracteriza como um das etapas mais importantes de todo o processo educacional na vida dos indivíduos, porque é nela que são desenvolvidas a motricidade, a atenção , a concentração, a imaginação entre outras capacidades essenciais na vida dos seres humanos .Os professores que atuam nessa modalidade de ensino podem contribuir para o desenvolvimento dessas capacidades essenciais no processo de alfabetização nas séries iniciais do Ensino Fundamental.(SANTOS.M,2016.p.14)

RELEDUC | ISE | v. 2 | n. 1 | fev. 2019 
Para que esta base realmente se torne um aparato eficaz na aquisição de conhecimentos posteriores, a proposta pedagógica deve estar alinhada atentando-se as particularidades do público da educação infantil. Sobre isso Maia reitera:

Ao pensar em propostas pedagógicas para essa faixa etária, precisaremos conhecer as concepções de desenvolvimento humano e aprendizagem para podermos ofertar uma proposta com qualidade e de acordo com as potencialidades de crianças entre zero e seis anos. Conhecer como elas aprendem, conhecem o mundo e se desenvolvem deve ser a base para todo o trabalho do educador, além de compreendermos a importância do lúdico. (MAIA. I 2016.p.9)

Ainda que a alfabetização propriamente dita só se inicie no primeiro ano do ensino fundamental, suas bases são lançadas bem antes disso, pois desde que nasce a criança é exposta a práticas sociais de leitura e escrita(MAIA.I,2016.p.6)

Mesmo expostas às práticas de leitura e escrita dentro ou fora do âmbito escolar,tais práticas não ocorrem de maneira linear, e podem vir a apresentar percalços durante este processo ensino-aprendizagem. Segundo Scoz (2013, p.56) o fenômeno da aprendizagem não é de fácil compreensão tanto em seus aspectos normais como patológicos; sendo necessário que se ofereça aos docentes uma orientação que lhes possibilite compreender os diferentes níveis evolutivos de cada criança.

BIMONTI complementa:

No entanto, devemos elucidar que a aprendizagem da leitura e escrita é um processo complexo que envolve vários sistemas e habilidades e não se deve esperar que um único fator seja responsável pela dificuldade apresentada para aprender. (BIMONTI, 2008. p.16)

Diante dessa e de outras questões é fundamental um aporte de uma equipe multidisciplinar ao educador afim de promover uma aprendizagem significativa de todos os educandos, principalmente os que apresentarem maiores dificuldades na alfabetização.

Lopes (2008) ressalta que:

Dessa forma, podemos nos referir a um trabalho multidisciplinar, isto é, uma ação conjunta de vários profissionais envolvidos com o processo de aprendizagem, respeitando, obviamente, o campo de atuação de cada especificidade. (LOPES, 2008, p.16).

Mediante a este cenário o psicopedagogo,tem como função primordial de colaborador na busca de soluções para os problemas de comportamento e aprendizagens, já que ele tem o

$$
\text { RELEDUC | ISE | v. } 2 \text { | n. } 1 \text { | fev. } 2019
$$


domínio de técnicas especializadas, orientando professores, pais e demais envolvidos, naquilo que se deve fazer em cada momento do processo de ensino com o intuito de amenizar os obstáculos encontrados no ambiente escolar em diversos níveis de ensino.

Para Bossa (1994, p. 23):

Cabe ao psicopedagogo perceber eventuais perturbações no processo de aprendizagem, participar da dinâmica da comunidade educativa, favorecendo a integração, promovendo orientações metodológicas de acordo com as características e particularidades dos indivíduos do grupo, realizando processos de orientação. Já que no caráter assistencial, o psicopedagogo participa de equipes responsáveis pela elaboração de planos e projetos no contexto teórico/prático das políticas educacionais, fazendo com que os professores, diretores e coordenadores possam repensar o papel da escola frente a docência e às necessidades individuais de aprendizagem da criança ou, da própria ensinagem.

O psicopedagogo, portanto em seu papel na instituição deve colaborar no que tange a orientações teórico/pratico a fim de auxiliar o docente diante de peculiaridades na prevenção das dificuldades de aprendizagem que podem surgir durante o processo de alfabetização.

\section{CONSCIÊNCIA FONOLÓGICA NA EDUCAÇÃO INFANTIL E A IMPORTÂNCIA DO LÚDICO}

Dentre os inúmeros conhecimentos prévios estimulados na educação infantil que antecedem a alfabetização nas séries iniciais,o trabalho com a consciência fonológica se faz pertinente pois concebida em um sentido amplo oportuniza o desenvolvimento de habilidades envolvendo rimas e sílabas -. por meio do brincar com as palavras - conhecimento este, importante para o aprendizado da escrita alfabética (BRANDÃO, 2016, p.78).

CAPOVILLA (2011) acrescenta que "A consciência fonológica refere-se tanto à consciência de que a fala pode ser segmentada quanto à habilidade de manipular tais segmentos (Bertelson\&DeGelder, 1989; Blischak,1994)" (CAPOVILL, 2011, p.85).

SOARES (2017 p.183) ainda salienta que as crianças são capazes de perceber as semelhanças das palavras por seus aspectos fonológicos devido a exposição tanto em ambiente familiar e instituições de Educação Infantil de textos do folclore que exploram rimas e aliterações por meio de parlendas, cantigas de ninar, cantigas de roda e trava línguas.

Brandão (2016, p.30) ainda ressalta que na Educação Infantil é essencial que o professor

$$
\text { RELEDUC | ISE | v. } 2 \text { | n. } 1 \text { | fev. } 2019
$$


realize um trabalho voltado a linguagem de maneira sistematizada, ou seja embasada em planejamento , organização do tempo e pedagógico e intencionalidade a fim de atingir as metas propostas.

\section{Sobre isso SOARES pontua:}

No entanto, para que essa sensibilidade à semelhança fonológica global entre palavras avance para uma atenção dirigida intencionalmente para os sons da palavra, sem consideração do significado dela, o que é base para a compreensão do princípio alfabético , é necessário desenvolve-la de forma sistemática por meio de atividades que levem a criança a reconhecer explicitamente rimas e aliterações e também a produzir rimas e aliterações (SOARES.M 2017 p.183).

Diante disso, faz-se necessário em suma que o professor assuma uma postura de aprendizado e obtenha saberes acerca da nossa língua e suas peculiaridades, traçando por conseguintes estratégias para a realização de atividades pertinentes a este tema.

Sabendo que a consciência fonológica é um dos fatores fundamentais para a aprendizagem da leitura e escrita alfabética, é necessário que os professores dêem lugar a sua instrução. Para tanta, é de fundamental importância que os professores conheçam um pouco da estrutura da língua, principalmente fonologia (BIMONTI, 2008, p.16).

Segundo Brandão (2016, p.64) Diferentes estudos tem mostrado que as crianças são capazes de manipular as dimensões sonoras das palavras, as habilidades de comparar palavras, suas semelhanças sonoras, segmentar palavras em silabas e compará-las de acordo com o tamanho, por meio das brincadeiras com as palavras.

ADAMS afirma que:

Felizmente, muitas das atividades que há tempos são desfrutadas pelas crianças em idade pré-escolar, envolvendo rima, ritmo, escuta e sons, são ideais para esse propósito. Na verdade, tendo em mente esse objetivo, todas essas atividades podem ser usadas, de forma mais eficaz, no sentido de ajudar a desenvolver a consciência fonológica (ADAMS, 2006, p.20)

Sobre isso Savage $(2015$, p.55) ainda pontua que embora formas simples de poesia podem ser usadas de maneira eficaz no desenvolvimento da consciência fonológica, o foco instrucional não pode ofuscar a alegria das crianças quando entram em contato com os versos, cantigas, parlendas e poesias infantis- belos exemplares da nossa cultura. 
ADAMS (2006, p. 32) ainda acrescenta que os jogos além do apelo infantil são também eficazes e que as crianças devem sentir que estão brincando, mesmo quando estiverem aprendendo.O lúdico portanto tem papel de protagonista quando se refere a construção de conhecimentos pois o mesmo possibilita uma aprendizagem significativa de diversos conteúdos, especialmente na construção da linguagem oral e escrita.

Como podemos verificar em (PACTO 2015):

Nesse sentido, afirmamos que os jogos, os brinquedos e as brincadeiras colaboram para uma vida mais significativa e prazerosa para a criança. Por isso, há muito tempo, os estudiosos da Educação defendem as atividades lúdicas como recursos para o desenvolvimento de ações pedagógicas significativas, como aquisição da leitura e da escrita, conceitos matemáticos, dentre outros (PACTO, 2015, p.24).

O RCNEI (1998) ainda complementa:

As poesias, parlendas, trava-línguas, os jogos de palavras, memorizados e repetidos, possibilitam às crianças atentarem não só aos conteúdos, mas também à forma, aos aspectos sonoros da linguagem, como ritmo e rimas, além das questões culturais e afetivas envolvidas. (RCNEI, 1998, p.141)

Essas práticas pertinentes e advindas da linguagem oral são de extrema importância, pois constituem um rico arcabouço que estimula o desenvolvimento pleno da criança no que refere a construção de seu próprio sujeito, de sua expressão oral e conhecimentos prévios para a aquisição de leitura e escrita.

Outro aspecto diz respeito à expressividade. Crianças pequenas gostam de brincar com as palavras que não conhecem só porque lhes soam engraçadas. Regidas pelo pensamento sincrético, buscam no efeito sonoro da rima e na repetição dos sons uma inspiração para brincar, um modo de expressão que é muito próximo do pensamento típico dessa idade. Um trabalho a partir de de quadrinhas populares, parlendas e trava-línguas oferece uma ótima oportunidade de imersão da criança na expressividade de sua língua .Ao memorizar esses textos que se precisa saber de cor para brincar, as crianças ganham um repertorio para as primeiras experiências de leitura (OLIVEIRA, 2012, p.215).

Essa maneira prazerosa pertinente à etapa da Educação infantil no processo ensino aprendizagem permite que as crianças obtenham um contato diversificado e lúdico com a consciência fonológica e que proporcione portando habilidades necessárias que estimulem o processo de alfabetização. ADAMS (2006) afirma ainda que: 
Ao educadores que ensinam consciência fonológica descobriram que, fazendo isso, aceleram o crescimento de toda de toda a turma em termos de leitura e de escrita, ao mesmo tempo em que reduzem a incidência de crianças com atraso na leitura .Além disso perceberam que, prestando atenção à consciência fonológica das crianças, tiram a fônica do campo do treinamento puro, tornando-a mais fácil de ser aprendida e mais interessante para os alunos. (ADAMS et al, 2006, p.17)

Com a utilização de jogos e a as atividades de análise fonológica chamam a atenção das crianças sobre as rimas, fonemas, ou seja, segmentos sonoros das palavras, tais propostas permitem as estas que reflitam sobre os princípios da escrita alfabética, ou seja a relação entre os sinais gráficos (letras) e a pauta sonora. (BRANDÃO, 2010, p.26)

Nosso sistema de escrita alfabética possui, portanto, esta estreita relação entre grafema e fonema torna -se fundamental para a aquisição da leitura e escrita e, portanto, justificam -se os inúmeros estudos acerca do tema.

Rimas e aliterações representam, pois, um nível de sensibilidade fonológica que se desenvolvido, pode trazer efeitos significativos para o processo de alfabetização :levam a criança a dirigir a atenção para a cadeia sonora das palavras, dissociando -a do significado ,colaborando assim para a superação do realismo nominal ; atividades podem levar a criança a perceber a possibilidade de segmentação das palavras ;finalmente, atividades que levem a criança a confrontar rimas e aliterações com sua representação escrita podem introduzir a compreensão da relação entre os sons e os grafemas que os representam, ou seja a compreensão do princípio alfabético. (SOARES, 2017, p.184)

Sobre isso GUEDES 2010 complementa que:

Estudos abordando esse tema têm afirmado que o desempenho em tarefas de consciência fonológica pode predizer como a criança irá se desenvolver as habilidades de leitura e de escrita, tendo sido correlacionado o sucesso quanto à consciência fonológica com o êxito no aprendizado da escrita alfabética. (GUEDES; GOMES, 2010, p.264)

Esta relação denota, portanto, a importância de estudos acerca desta estreita relação entre a consciência fonológica e sua instrução em pré-escolares e o processo de alfabetização e ainda tem despertado o interesse de pesquisadores de diversas línguas alfabéticas. ADAMS salienta que: 
Consciência fonológica é, atualmente, um assunto de grande importância Crianças que tem consciência dos fonemas avançam de forma mais fácil e produtiva para a escrita e para a leitura criativas. As que não tem consciência dos fonemas correm sérios riscos de não conseguirem aprender a ler. (ADAMS et al, 2006, p.17)

Pesquisas internacionais vêm demonstrando que crianças com atrasos em consciência fonológica geralmente também apresentam atrasos na leitura e escrita, e que procedimentos para desenvolver a consciência fonológica podem prevenir e remediar tais atrasos. (CAPOVILLA, 2011, p.66).

ADAMS (2006, p.21) ainda salienta que pesquisas mostram claramente que a consciência fonologia pode ser desenvolvida por meio de instrução e que ao fazê-lo significa acelerar a posterior aquisição de leitura e escrita pela criança.

Numerosas pesquisas comprovam a correlação entre consciência fonológica e progresso na aprendizagem da leitura e escrita. Sendo assim, jogos para desenvolvimento da consciência fonológica, se realizados sistematicamente na educação infantil, criam condições propícias, até mesmo necessárias, para a apropriação do sistema alfabético. (SOARES, 2017, p.142)

O docente ao estimular a reflexão consciente sobre palavras e partes destas, possibilita que as crianças percebam desde cedo as regras que combinam letras e sons (principio alfabético) e que as letras representam os sons da fala.

Um importante obstáculo para a maioria das crianças é compreender o princípio alfabético: palavras escritas contêm combinações de unidades visuais (letras ou combinações de letras) que são sistematicamente relacionadas às unidades sonoras das palavras (fonemas). (FREITAS, 2004, p.30)

FREITAS (2004) ainda pontua dois níveis de consciência fonológica:

A identificação de rimas por crianças pequenas não alfabetizadas, por exemplo, pode indicar a existência de uma consciência implícita, ou seja, de uma sensibilidade às similaridades fonológicas. Por outro lado, julgamentos mais refinados, como o isolamento de fonemas de uma palavra, exigem que a criança apresente um nível explícito de consciência fonológica, manipulando conscientemente a estrutura sonora (FREITAS, 2004, p.18).

Para que o trabalho com a consciência fonológica na educação infantil seja eficaz, se faz necessário que o mesmo seja organizado , onde estas atividades e vivências com a linguagem sejam incorporadas na rotina diária destes educandos e possibilite a reflexão sobre as dimensões sonoras e escrita das palavras de maneira lúdica. 
Sobre isso BRANDÃO (2016.p.69) sugere a criação de jogos de regras como jogo da memória , baralho, dominó; onde por meio desses as crianças possam refletir sobre as palavras, comparando -as e segmentando -as é uma tarefa que o docente pode realizar tratando assim de maneira lúdica essas aprendizagens tão pertinentes.

\section{CONSIDERAÇÕES FINAIS}

Muitos são os desafios a serem enfrentados em âmbito educacional, o maior destes desafios é a tão almejada qualidade na educação, uma escola em que todos os educandos se apropriem do conhecimento e sejam autores de sua própria trajetória, aprendendo a aprender e sejam por fim sujeitos autônomos.

Diante desta meta tão necessária o professor deve buscar novos conhecimentos e melhorias em sua prática pedagógica, sendo este um “eterno aprendiz”. Nesta missão o docente pode ter ao seu auxilio o psicopedagogo que atuando nas instituições escolares, pode agir como um colaborador afim de orientar sobre o processo de aprendizagem e suas possíveis dificuldades.

Por meio deste estudo foi possível através do embasamento teórico constatar como a consciência fonológica se faz necessária como pré-requisito para a alfabetização e que se estimulada em pré-escolares pode atenuar possíveis dificuldades durante a alfabetização propriamente dita.

Este estímulo a consciência fonológica deve ocorrer aliado ao elemento lúdico, pois por meio dos jogos e brincadeiras os conhecimentos sobre a linguagem oral e seus pormenores são construídos ainda proporcionam o desenvolvimento da socialização, comunicação, expressão e construção do conhecimento por meio da criatividade, sensibilidade e afetividade envolvidas durante estas brincadeiras, trabalhando portanto características inerentes ao ser humano, tudo isso de maneira dinâmica e prazerosa para uma aprendizagem significativa, aprendizagem esta que desperte no aluno o desejo de aprender.

\section{REFERÊNCIAS}

ADAMS, M. et al. Consciência fonológica em crianças pequenas. Porto Alegre: Artmed, 2006. 
BIMONTI, R. A importância da consciência fonológica na educação Infantil. 2008. 43 f. Trabalho de conclusão de curso de Especialização em Distúrbio de aprendizagem-Centro de referência em distúrbios de aprendizagem, São Paulo, 2008.

BOSSA, Nádia A. A Psicopedagogia no Brasil: construções a partir da prática. Porto Alegre: Artes Médicas Sul, 1994.

BRANDÃO, A; ROSA, E (Orgs.) Ler e escrever na Educação Infantil: Discutindo práticas pedagógicas. 2.ed. Belo Horizonte: Autêntica, 2016.

BRASIL. Lei de Diretrizes e Bases da Educação Nacional. DF. 1996.

BRASIL. Ministério da Educação e do Desporto. Secretaria de Educação Fundamental. Referencial curricular nacional para a educação infantil. Brasília: MEC/SEF, 1998.

BRASIL. Ministério da Educação, Secretaria de Educação Básica, Diretoria de Apoio à Gestão Educacional. Pacto Nacional pela Alfabetização na Idade Certa. A criança no ciclo de alfabetização. Caderno 02. Brasília: MEC, SEB, 2015.

CAPOVILlA, C. F; SEABRA, G. A Problemas de leitura e escrita: Como identificar, prevenir e remediar numa abordagem fônica. 6 ed. São Paulo, 2011.

FREITAS, M. C. G. Consciência fonológica e aquisição da escrita: Um estudo Longitudinal.2004. Tese (Doutorado em Linguística aplicada) Pontifícia Universidade Católica do Rio Grande do Sul. Porto Alegre, 2004.

GUEDES, M; GOMES, C. Consciência fonológica em períodos pré e pós -alfabetização. Cadernos de Letras da UFF- Dossiê: Letras e cognição, Rio de Janeiro, n. 41, p.263-281, 2010.

LOPES, S. O processo de avaliação e intervenção em Psicopedagogia. Curitiba, 2008.

MAIA, I. Alfabetização e Letramento da Educação Infantil: Perspectiva de aprendizagem. 2016. 31 f. Trabalho de conclusão de curso (Graduação em Pedagogia) - Universidade Federal do Rio Grande do Norte, Martins-RN,2016.

MIRANDA, M. Problemas de aprendizagem na alfabetização e intervenção escolar. 2.ed. São Paulo: Cortez, 2009.

OLIVEIRA, Z. et al. O trabalho do professor na educação infantil. 1 ed. São Paulo: Biruta, 2012.

SAVAGE, J. Aprender a ler e a escrever a partir da fônica: Um programa abrangente de ensino. 4 ed. Porto Alegre: AMGH, 2015.

SCOZ, B. Psicopedagogia e realidade escolar: o problema escolar e de aprendizagem. Rio de Janeiro, 2013. 
SOARES, M. Alfabetização e letramento. 7 ed. São Paulo: Contexto, 2017.

SOARES, M. Alfabetização: A questão dos métodos. 1 ed. São Paulo: Contexto, 2017. 